Research Paper

\title{
FasL Expression on Human Nucleus Pulposus Cells Contributes to the Immune Privilege of Intervertebral Disc by Interacting with Immunocytes
}

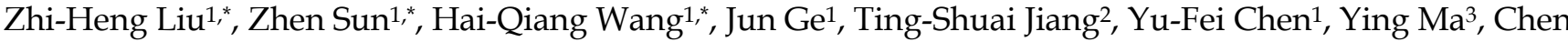 \\ Wang ${ }^{4}$, Sheng $\mathrm{Hu}^{4}$, Dino Samartzis ${ }^{5}$, Zhuo-Jing Luo ${ }^{1, \otimes}$ \\ 1. Department of Orthopaedics, Xijing Hospital, Fourth Military Medical University, 127 Changle Western Road, Xi'an, P. R. China. \\ 2. Department of Ophthalmology, Xijing Hospital, Fourth Military Medical University, 127 Changle Western Road, Xi'an, P. R. China. \\ 3. Department of Immunology, Fourth Military Medical University, 127 Changle Western Road, Xi' an, P. R. China. \\ 4. Department of Anesthesiology, Fourth Military Medical University, 127 Changle Western Road, Xi'an, P. R. China \\ 5. Department of Orthopaedics and Traumatology, University of Hong Kong, Pokfulam, Hong Kong, SAR China. \\ * These authors contribute equally to this work.
}

$\triangle$ Corresponding author: Zhuo-Jing Luo. zjluo@fmmu.edu.cn.

(c) Ivyspring International Publisher. This is an open-access article distributed under the terms of the Creative Commons License (http://creativecommons.org/ licenses/by-nc-nd/3.0/). Reproduction is permitted for personal, noncommercial use, provided that the article is in whole, unmodified, and properly cited.

Received: 2013.03.10; Accepted: 2013.06.17; Published: 2013.06.2I

\begin{abstract}
The mechanisms of immune privilege in human nucleus pulposus (NP) remain unclear. Accumulating evidence indicates that Fas ligand (FasL) might play an important role in the immune privilege of the disc. We aimed for addressing the role of FasL expression in human intervertebral disc degeneration (IDD) and immune privilege in terms of the interaction between NP cells and immunocytes via the FasL-Fas machinery. We collected NP specimens from 20 patients with IDD as degenerative group and 8 normal cadaveric donors as control. FasL expression was detected by qRT-PCR, western blotting and flow cytometry (FCM). We also collected macrophages and CD8 ${ }^{+}$ $T$ cells from the peripheral blood of patients with IDD for co-cultures with NP cells. And macrophages and $\mathrm{CD}^{+} \mathrm{T}$ cells were harvested for apoptosis analysis by FCM after 2 days of co-cultures. We found that FasL expression in mRNA, protein and cellular resolutions demonstrated a significant decrease in degenerative group compared with normal control $(p<0.05)$. FCM analysis found that human NP cells with increased FasL expression resulted in significantly increased apoptosis ratio of macrophages and $C D 8^{+} \mathrm{T}$ cells. Our study demonstrated that FasL expression tends to decrease in degenerated discs and FasL plays an important role in human disc immune privilege, which might provide a novel target for the treatment strategies for IDD.
\end{abstract}

Key words: intervertebral disc degeneration, FasL, immune privilege, macrophage, $\mathrm{CD} 8^{+} \mathrm{T}$ cell.

\section{Introduction}

Intervertebral disc degeneration (IDD) is a major cause of many spinal disorders [1,2]. Over the past decade, the underlying mechanisms of IDD have been well documented in terms of biomechanics [3], cell apoptosis [4, 5], deregulated genes and microRNAs (miRNAs) [6, 7]. Moreover, studies with human disc cells, especially focusing on nucleus pulposus (NP) cells, are seldom found in the literature. Despite intensive basic and clinical pieces of studies aiming for addressing the issues, the physiopathological mechanisms of IDD remain yet speculative with particular reference to the maintenance of immune privilege. The immune privilege of tissues is ascribed not only to the physiological blood-tissue barrier, but the local 
expression of Fas ligand (FasL).

As the largest avascular organ in the human body, the intervertebral disc is isolated from the host immune system [8]. Many pieces of evidence indicate the immune privilege of the disc, the chief of which is NP [9-11]. As an important death receptor of immune privilege, FasL is expressed on activated T cells, NK cells, and in immune privileged sites [12], i.e., eyes, ovary, placenta[13-15], transplantation organs [16-20]. Various levels of the expression of FasL have been noted in both degenerative and non-degenerative NP [21-23]. It has been consequently hypothesized that the Fas-FasL death complex may play a role upon maintaining the immune privilege of the disc.

Cross-linking of FasL with Fas leads to apoptosis via a complex signaling pathway [24]. In immune privileged sites, activated cytotoxic $\mathrm{T}$ lymphocytes (CTLs) and macrophages can recognize target cells and subsequently become activated. The FasL in these cells binds to Fas on the surface of the target cells and induces apoptosis. Alternatively, when the target cells express FasL, CTLs or macrophages might die of apoptosis via the same pathway. This mechanism protects the disc from auto-immune attack [13].

The FasL expression of the disc samples from patients with IDD and cadavers was seldom reported due to the paucity of human samples. It has been noted that FasL exists in human intervertebral disc cells, especially in NP cells [22, 25]. Furthermore, we found that deregulated miR-155 promotes Fas-mediated apoptosis in human intervertebral disc degeneration by targeting FADD and CASP3. However, the FasL derivation remains largely unknown. Nevertheless, the difference of FasL expression between degenerative and normal NP tissues is still unclear. Accordingly, the purpose of this study was to address the role of FasL expression in human intervertebral disc degeneration (IDD) and immune privilege in terms of the interaction between NP cells and immunocytes via the FasL-Fas machinery.

\section{Materials and Methods}

\section{Sample collection}

The NP samples and peripheral blood mononuclear cells (PBMCs) collection for experimental application was approved by our institutional Ethics Review Board of Xijing hospital (No. 20090611-3, No. 20111103-7). Moreover, we obtained written informed consents from each patient. For cadaveric donors, we obtained the same style of written informed consents from their relatives. Human NP specimens were collected from patients with IDD undergoing discectomy as degenerative NP samples $[n=20$; average age
43.4 \pm 5.4 (range 35-52)] and normal cadaveric donors as control [ $\mathrm{n}=8$; average age $41.8 \pm 3.6$ (range 37-47)] (Table 1). The cadavers and patients included in control and experimental groups are matched for age, with no smoking, diabetes, hypertension and radicular symptoms, etc. All the the patients with disc degeneration were strictly selected by MRI and intraoperative findings to exclude NP samples that had herniated outside the annulus. The degeneration degree was graded by magnetic resonance imaging (MRI) according to the Pfirrmann's grading system [26]. As for the cadavers, MRI data in records were collected. All the samples were dissected carefully under magnification and subsequently managed under various schemes according to the corresponding procedures.

Table I. Demographic data of cadaveric donors and patients.

\begin{tabular}{lllll}
\hline NO. & Age & Gender & Level & Degree* \\
\hline Normal control & & & & \\
1 & 44 & M & L4/5 & I \\
2 & 38 & M & L4/5 & I \\
3 & 37 & F & L4/5 & I \\
4 & 45 & M & L4/5 & I \\
5 & 47 & M & L4/5 & I \\
6 & 39 & F & L4/5 & I \\
7 & 45 & M & L4/5 & I \\
8 & 39 & M & L4/5 & I \\
IDD Group & & & & \\
9 & 47 & F & L4/5 & IV \\
10 & 52 & M & L4/5 & IV \\
11 & 43 & F & L4/5 & V \\
12 & 36 & F & L4/5 & IV \\
13 & 42 & M & L4/5 & V \\
14 & 50 & F & L5/S1 & IV \\
15 & 45 & F & L5/S1 & IV \\
16 & 41 & M & L4/5 & IV \\
17 & 38 & M & L4/5 & IV \\
18 & 35 & F & L5/S1 & V \\
19 & 39 & M & L4/5 & IV \\
20 & 42 & F & L5/S1 & IV \\
21 & 52 & M & L4/5 & IV \\
22 & 43 & M & L4/5 & IV \\
23 & F & L4/5 & IV \\
24 & M & L4/5 & IV \\
25 & & & IV \\
26 & F4/5 & IV \\
27 & F & L5/S1 & IV \\
28 & 36 & M & \\
\hline
\end{tabular}

* Pfirrmann's grading system. 


\section{NP cell cultures}

Human NP cells were isolated from intervertebral disc tissues during surgical procedures for patients and dissection for cadaveric donors. After carefully washed, annulus fibrosus and cartilaginous endplate were removed under the microscope. The remain tissues were then minced and digested for 40 min at $37^{\circ} \mathrm{C}$ in PBS with $0.25 \%$ pronase (Gibco-BRL, Carlsbad, CA, USA). Then solution was removed, remaining tissue washed, and digested for $4 \mathrm{~h}$ in PBS with $0.025 \%$ collagenase type II (Invitrogen). The digest was then washed three times and filtered through a $45-\mu \mathrm{m}$ pore-size nylon mesh. Cells were plated and expanded for 3 weeks in DMEM/F12-based culture medium, containing 15\% fetal bovine serum (FBS; Gibco-BRL) and 1\% penicillin/streptomycin (Invitrogen) in a $5 \% \mathrm{CO}_{2}$ incubator. The culture medium was changed every three days. NP cells of Passage 1 or 2 were used for our experiments.

\section{Western blotting analysis}

To determine the FasL expression level of NP cells in IDD patients and cadaveric donors, the cultured NP cells were trypsinized. Prepare total cell lysates by solubilizing cells in 2X SDS sample buffer. Following electrophoresized in $10 \%$ gel, proteins were transfered to PVDF membrane. The membranes were incubated for $1 \mathrm{~h}$ at room temperature with rabbit polyclonal antibody specific to FasL (Santa Cruz Biotechnology, CA, USA), and mouse monoclonal antibody specific to $\beta$-actin (Sigma, Saint Louis, USA) as control. Antibody labeling was identified using IRDye 800 anti-rabbit or anti-mouse IgG antibody (LI-COR Biosciences, Nebraska, USA). Expression levels were analyzed by LI-COR Odyssey Imaging System.

\section{RNA isolation and qRT-PCR}

NP cells from cadavers and patients with IDD were harvested, and total RNA was isolated using the Trizol reagent (Invitrogen, Carlsbad, CA, USA) according to the manufacturer's instructions.

Reverse transcription to cDNA was performed using a High-Capacity cDNA Archive Kit (ABI, Foster City, CA, USA). Predesigned primers for human FasL and human GAPDH as control were purchased from Sangon (Sangon, Shanghai, China). RNA concentrations were measured using a NanoDrop instrument ( NanoDrop, Wilmington, DE, USA). The levels of FasL mRNA were normalized to GAPDH mRNA controls. All RT reactions, including GAPDH controls, were run in triplicate in a GeneAmp PCR 9700 Thermocycler (ABI). The relative amounts of FasL mRNA were calculated using the comparative $\mathrm{Ct}\left(2^{-\Delta \Delta \mathrm{C} t}\right)$ method.
The primers used in the study included: FasL forward: 5'- TTGCCTTGGTAGGATTGG-3', reverse: 5'-ATGGACCTTGAGTTGGACTT-3'; GAPDH forward: 5'-GCACCGTCAAGGCTGAGAAC-3', reverse: 5' - TGGTGAAGACGCCAGTGGA-3').

\section{PBMCs collection}

PBMCs were isolated from whole blood by Ficoll-Hypaque density gradient centrifugation as reported previously. Briefly, the peripheral blood was obtained in heparinized vacutainer collection tubes from IDD patients and diluted 1:3 in RPMI-1640 (Gibco, Grand Island, NY, USA).Then $30 \mathrm{~mL}$ diluted blood was slowly layered over $15 \mathrm{~mL}$ Ficoll-Paque (GE Healthcare, Piscataway, NJ, USA), and centrifuged at $800 \times \mathrm{g}$ for $30 \mathrm{~min}$ at room temperature. The PBMCs were subsequently collected for macrophage separation.

\section{Isolation and cultures of macrophages from patients with IDD}

The PBMCs collected from the patients with IDD were washed three times with RPMI-1640, and plated in tissue culture dishes (BD Bioscience, San Diego, CA, USA) at $3 \times 10^{6}$ cells/mL in RPMI-1640 supplemented with $2 \mathrm{mM}$ L-glutamine (Gibco), $100 \mathrm{U} / \mathrm{mL}$ penicillin (Gibco), $100 \mu \mathrm{g} / \mathrm{mL}$ streptomycin (Gibco), $0.1 \mathrm{mM}$ sodium pyruvate (Gibco), $1 \%$ non-essential

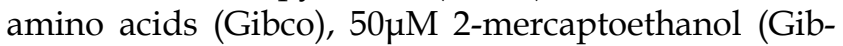
co), and 10\% fetal bovine serum (Gibco). After $24 \mathrm{~h}$, the PBMCs in tissue culture dishes were washed gently with RPMI-1640 to remove a majority of the non-adherent cells. The monocytes which had been adherent in the dishes were cultured for an additional five days supplemented with $18 \mathrm{ng} / \mathrm{mL}$ GM-CSF (PeproTech, Rocky Hill, NJ, USA) and $20 \mathrm{ng} / \mathrm{mL}$ M-CSF (PeproTech). Thereafter, the cells were washed with RPMI-1640 to remove the non-adherent or dead cells. The remaining adherent cells that had been induced to differentiate into macrophages were scraped from the plate and stained with the monoclonal antibody CD68-PE (eBioscience, San Diego, CA, USA) in FCM analysis to confirm the purity of the cells prior to the next steps.

\section{Isolation of $\mathrm{CD}^{+} \mathbf{T}$ cells}

$\mathrm{CD}^{+} \mathrm{T}$ cells were positively isolated from the whole blood of IDD patients using the $\mathrm{CD}^{+} \mathrm{T}$-cell Positive Isolation Kit (Invitrogen Dynal AS, Norway) according to the manufacturer's instructions. Over $90 \%$ of the $\mathrm{CD}^{+} \mathrm{T}$-cell isolation was confirmed by FCM analysis with monoclonal antibody CD8a-APC (eBioscience, San Diego, CA, USA). 


\section{Up-regulation of FasL with lentiviral vector}

The lentiviral vector labeled with green fluorescent protein (GFP) encoding FasL and a scrambled sequence as control were purchased from Genechem. Human NP cells were plated at a density of $1.5 \times 10^{5}$ cells/well in a 24-well plate in a final volume of $250 \mu \mathrm{l}$ complete medium. Viral solutions at a multiplicity of infection (MOI) of 10 were added to NP cells. Following $10 \mathrm{~h}$ of incubation at $37^{\circ} \mathrm{C}$, the cells were allowed to recover over the ensuing $96 \mathrm{~h}$ in culture medium. Culture flasks were detected by fluorescent microscopy to verify cell transfection.

\section{Indirect co-cultures of NP cells and immuno- cytes}

Transwell inserts $(0.4 \mu \mathrm{m}$ pore-size) were utilized for non-contacting co-culture in six-well plates. The co-culture ratio is 50:50, consisted of NP cells with $\mathrm{CD} 8{ }^{+} \mathrm{T}$ cells or macrophages from the same patient. $\mathrm{NP}$ cells were plated into six-well plate $\left(1.5 \times 10^{6}\right.$ per well) with $10 \%$ DMEM/F12 culture medium mentioned above, macrophages or $\mathrm{CD}^{+} \mathrm{T}$ cells $\left(1.5 \times 10^{6}\right.$ per well) were plated into Transwell inserts respectively with same culture medium, respectively. Eight groups with different combinations of cell types were defined in this study (Table 2). Macrophage and $\mathrm{CD} 8^{+} \mathrm{T}$ cell were harvested after 2 days of culture for FCM apoptpsis analysis.

Table 2 Groups for co-cultures of human NP cells and immunocytes

\begin{tabular}{|c|c|c|c|c|c|}
\hline \multirow[t]{2}{*}{ Group } & \multicolumn{3}{|c|}{ NP cells } & \multicolumn{2}{|c|}{ Immunocytes } \\
\hline & IDD & $\begin{array}{l}\text { Up-regulated } \\
\text { FasL }\end{array}$ & $\begin{array}{l}\text { Lentiviral } \\
\text { control }\end{array}$ & macrophages & $\begin{array}{l}\mathrm{CD}^{+} \mathrm{T} \\
\text { cells }\end{array}$ \\
\hline 1 & + & & & + & \\
\hline 2 & & + & & + & \\
\hline 3 & & & + & + & \\
\hline 4 & & & & + & \\
\hline 5 & + & & & & + \\
\hline 6 & & + & & & + \\
\hline 7 & & & + & & + \\
\hline 8 & & & & & + \\
\hline
\end{tabular}

\section{Flow cytometry (FCM) analysis}

To address apoptosis in macrophages and CD8 ${ }^{+}$ $\mathrm{T}$ cells after co-cultures, we performed FCM with Annexin V-FITC/PI (BD Biosciences, San Diego, CA, USA) staining upon the aforementioned treated cells, In brief, after washing twice with PBS, $1 \times 10^{6}$ cells were re-suspended in binding buffer. Annexin V-FITC and PI were added and then incubated at room temperature for $15 \mathrm{~min}$. The samples were then analyzed by FCM. Each experiment was repeated for at least three times.

\section{Statistical analysis}

Analysis of two-group parameters was performed with Student's t-test. Comparisons of multiple group data were performed with ANOVA test. The threshold of significance was set as $P$-value $<0.05$. The statistical analysis was performed with the SPSS 12.0 statistical package (SPSS, Chicago, IL, USA).

\section{Results}

\section{FasL expressed in human degenerative and normal NP cells with different resolutions}

The levels of mRNA expression of FasL in NP cells of non-degenerative group were significantly higher than those of the degenerative group (Figure 1A). Western blotting analysis further showed that the intensity of FasL in non-degenerated group was higher than that in the degenerated group (Figure 1B). Quantitative analysis revealed that the average FasL ratio in the degenerated group was $56 \% \pm 0.09$, whereas the average FasL ratio in the non-degenerated group was $89 \% \pm 0.12(p<0.05)$.

To compare FasL expression in degenerated and non-degenerated tissues, we also performed FCM analysis to identify the level of FasL in NP cells quantitatively. As shown in Figure 1C, the average ratio of FasL positive cells $(68.8 \% \pm 0.072)$ in non-degenerative $\mathrm{NP}$ cells is significantly higher than in degenerative NP cells $(35.4 \% \pm 0.053)(p<0.05)$.

\section{Up-regulated FasL of NP cells resulted in in- creased immunocyte apoptosis after co-cultures}

The cultured NP cells from patients with IDD in our study were in good growing condition (Figure 2A). Macrophages were successfully isolated and cultured (Figure 2B). The purity of macrophages and $\mathrm{CD}^{+} \mathrm{T}$ cells was detected by FCM. The GFP-expressing lentiviral vector transfection at a MOI of 10 encoding FasL resulted in high-level GFP expression in NP cells (Figure 2C). FCM detection revealed the apoptosis of immunocytes in different groups (Figure 3A). As for macrophages without co-cultures, the apoptosis rate was $4.8 \% \pm 0.007$. Approximately $6.5 \% \pm 0.0075$ macrophages were apoptotic when cultured with IDD NP cells. It was noteworthy that NP cells with up-regulated FasL resulted in about $17.5 \% \pm 0.012$ apoptosis rate of macrophages 
$(p<0.05)$. In the lentiviral-control group with scrambled sequence, the apoptosis rate of macrophages was $6 \% \pm 0.008$ (Figure 3B). Similar findings were observed in CD8 ${ }^{+} \mathrm{T}$ cells co-cultured with NP cells (Figure 3C).

\section{Discussion}

IVD degeneration is the major cause in neck or low back pain and disc herniation, which are the most common disorders leading to morbidity [27]. Apoptosis in IVD was initially reported by Gruber in 1998. And more and more evidences indicating that apoptosis plays an important role in human degenerative diseases. As one of the most important pathways of apoptosis, cell surface death receptor pathway is crucial in IVD process. In death receptor pathway, liga-
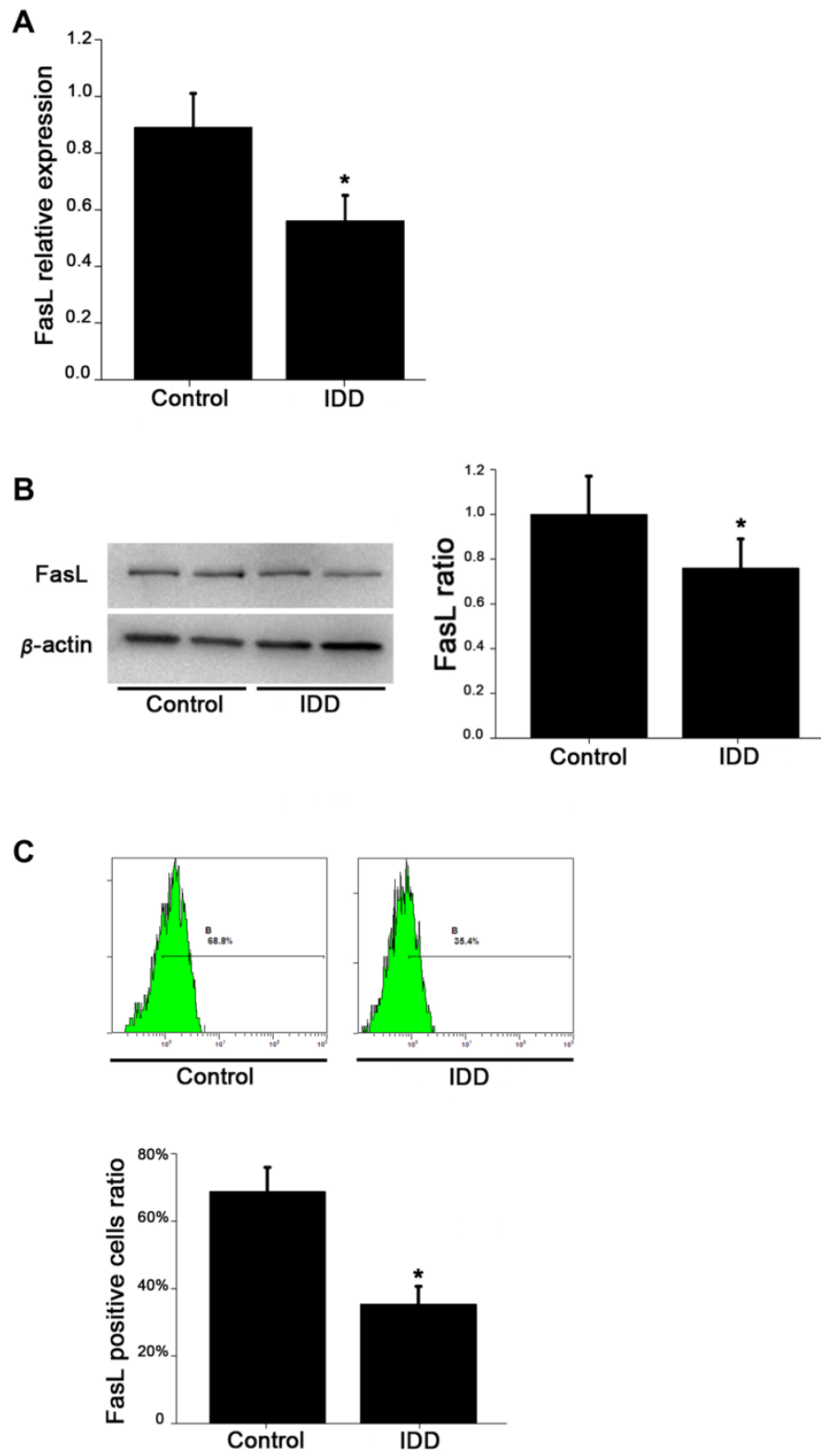

tion of Fas ligand to the Fas receptor on the cell membrane leads to the recruitment and activation of caspase-8, which will activates downstream caspases and results in apoptosis [27]. This mechanism also works in some autoimmune diseases, helps to maintain the balance of self-antigen and immune system.

We found that FasL expression in non-degenerated NP was significantly higher than in degenerated discs. So far, the study is the first in successfully establishing an in vitro model addressing the interaction of human NP cells and immunocytes. By modulating the FasL expression in degenerative NP cells co-cultured with immunocytes, we found that the degenerative NP cells with up-regulated FasL resolution would induce the apoptosis of invaded macrophages and $\mathrm{CD}^{+} 8 \mathrm{~T}$ cells, which contributes to the immune privilege of NP. Furthermore, this study is the first clarifying the underlying mechanisms of immune privilege of human intervertebral disc via FasL-Fas network.

The immune privilege of NP is not only due to the simple physiological barrier, but FasL expression as molecular mechanisms. Most immune privileged organs express FasL [13, 28-30]. Previously studies on the expression of FasL in NP cells from normal intervertebral disc of mature Sprague-Dawley rats and humans suggested that the Fas-FasL system may play a key role as the underlying mechanisms for maintaining the immune privilege of the disc [22]. FasL expression levels alter in NP during intervertebral disc formation [31]. The apoptosis in human NP is closely linked with autocrine or paracrine FasL mechanisms [10, 25]. However, most studies used NP samples from herniated lumbar disc, animals, and patients with scoliosis [23], which might not well represent the degeneration process in the body.

Fig I. FasL expression of NP cells in different levels from degenerative and normal NP. A. QRT-PCR analysis of Fas $L$ expression. B. Western blotting detection of FasL expression. C. Flow cytometry detection of FasL positive cells. Data are representative of six independent experiments. Error bars represent SEM. $* p<0.05$. 
A

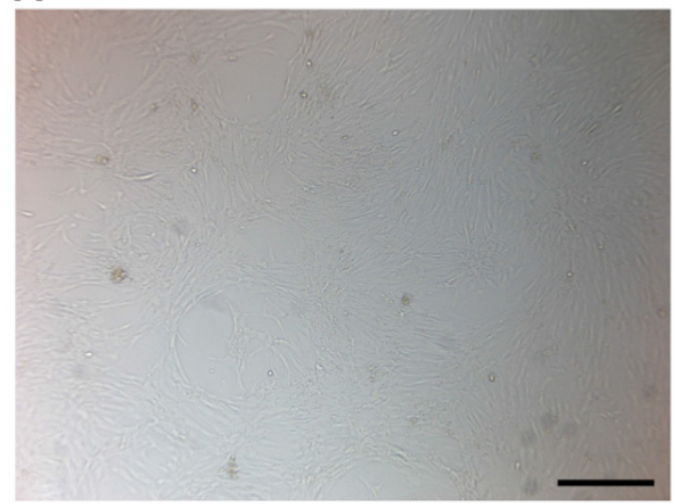

C

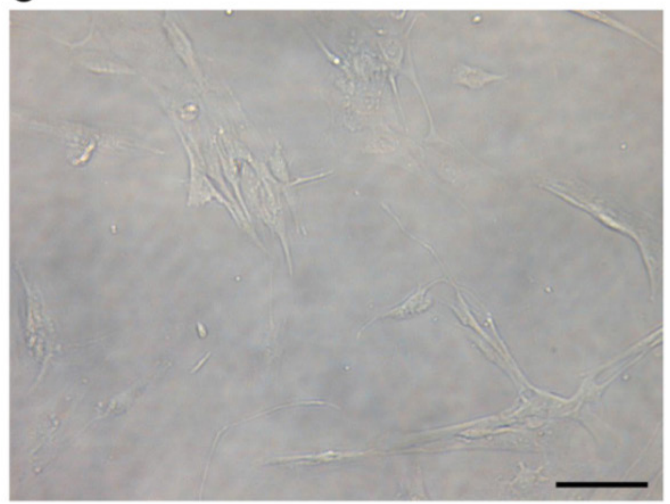

B
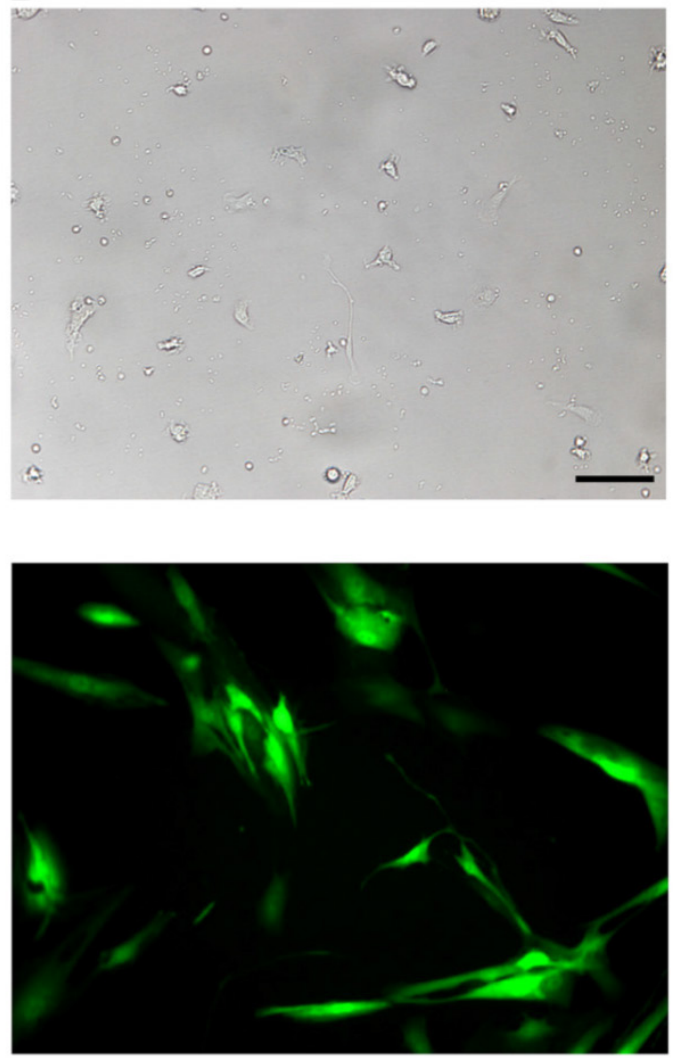

Fig 2. NP cells, macrophages and $C D 8^{+} T$ cells from patients with intervertebral disc degeneration were detected. A. Cultured NP cells for 14 days. Scale bars $=500 \mu \mathrm{m}$. B. Cultured macrophages for 7 days from peripheral blood of patients with disc degeneration. Scale bars $=50 \mu \mathrm{m}$. $\mathbf{C}$. Brightfield (left) and fluorescent (right) microscopy of human NP cells $96 \mathrm{~h}$ following transfection with lentivirus labeled with green fluorescent protein. Scale bars $=20 \mu \mathrm{m}$.

In this study, we collected non-degenerative cadaveric disc specimens as normal control. Moreover, we performed comprehensive analysis on FasL expression by qRT-PCR, western blotting and FCM. We carefully removed annulus fibrosus and cartilaginous endplate under the microscope in aseptic conditions due to the high degree of sensitivity of NP tissues. Our results based upon the multiple lines of evidence indicate a significant decrease of FasL expression in degenerative NP compared with normal discs in humans.

Our study clarified the mechanisms of the role of FasL-Fas network in human NP and shed light on the derivation of FasL in human disc. NP has been suggested to trigger an autoimmune response if exposed to the immune system in animal experiments as well as in patients with disc herniation [27, 32-35]. Both FasL and Fas are expressed by human $T$ lymphocytes [36] and NP cells [21, 22, 25]. FasL is one of the major effectors of CTLs to destroy target cells [37, 38]. As in most immune privileged organs, the FasL-Fas network is involved in the apoptotic pathways and im- mune privilege [12]. It is well established that eyes, as a typical immune privileged site, constitutively expresses FasL to control the spread of inflammation by killing Fas positive lymphoid cells that invade the tissue [13]. As well, FasL plays key roles in CTL-mediated tissue destruction under pathological conditions such as graft-versus-host disease (GVHD) [39] and experimental autoimmune diseases [40, 41]. Soluble and membrane-bound FasL can activate a cascade of caspases that culminates in apoptosis via binds to cell surface Fas $[42,43]$. However, the role of FasL-Fas network in human NP cells has not been clarified until now. We found that FasL expression in non-degenerative cadaveric NP samples is higher than in that in degenerative NP (grade IV and V). In normal NP, the expression of FasL could induce the apoptosis of immune cells. However, in the scenario of degenerated NP, FasL expression decreases, which was further confirmed by our preliminary study since we tried to down-regulate FasL expression via RNAi but failed. The apoptosis rate between immune cell group and immune cells co-cultured with NP cell 
group is not statistically different because of the low level expression of FasL in degenerated NP. Our findings indicate that the combination of FasL of normal NP cells to Fas positive $\mathrm{T}$ cell triggers the apoptosis of CTLs, which help keep the immune privileged condition of NP. Co-cultures of human NP cells with up-regulated FasL with auto-CD8 ${ }^{+} \mathrm{T}$ cells and macrophages, the apoptosis ratio of immunocytes significantly increased. These results suggest that FasL plays an important role in the immune privilege of human NP.

Despite our de novo in vitro model, we acknowledge that several shortcomings exist in our
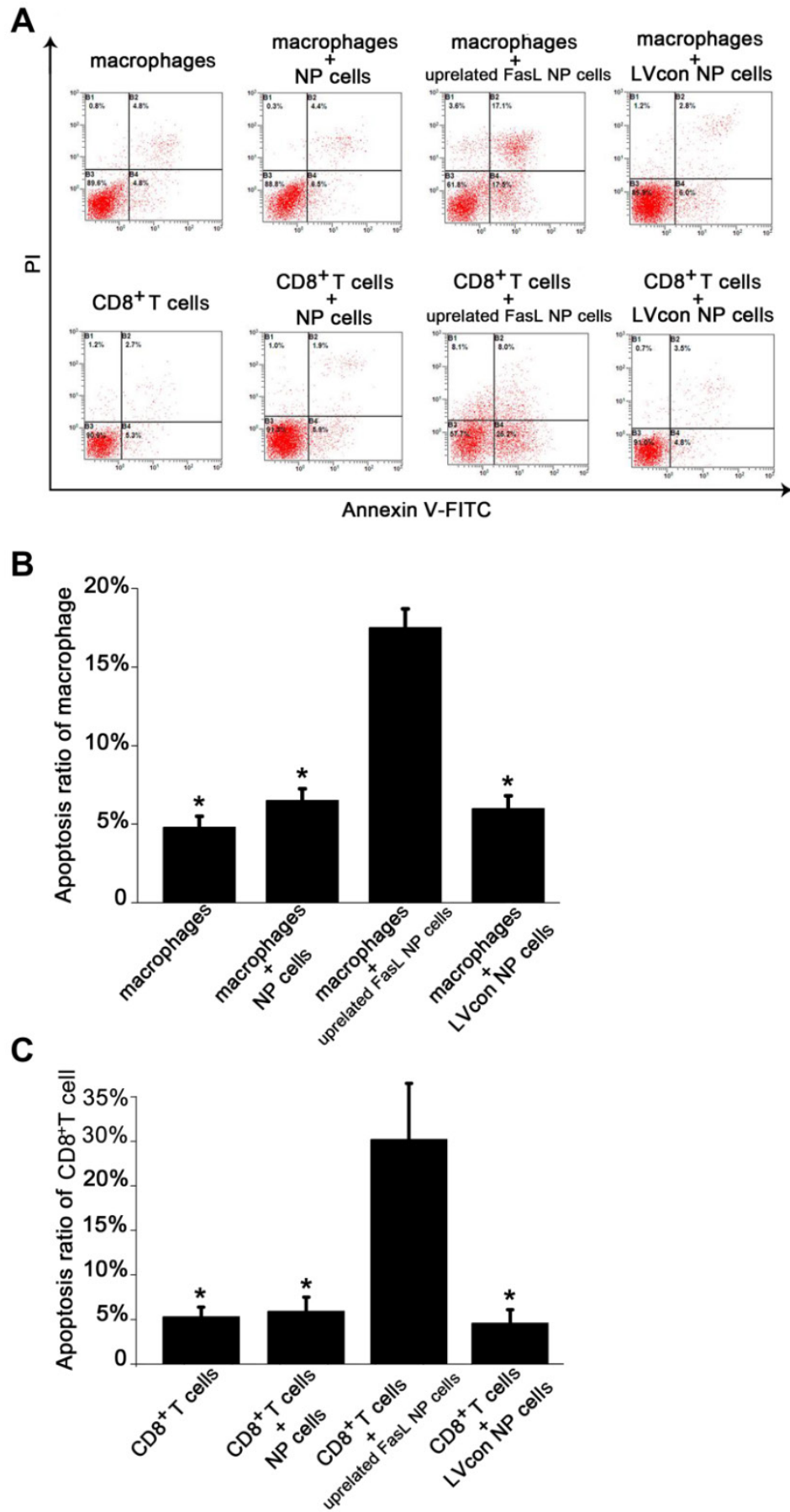

study. First, we didn't compare living patient degenerative NP cells with living patient normal NP cells because of clinical and ethical reasons. Secondly, we only up-regulated the FasL expression of NP cells by lentiviral vector without down-regulating the expression. This is partly due to the low expression level of FasL in NP tissue in our preliminary study (data not shown). Furthermore, we selected macrophages and $\mathrm{CD}^{+} \mathrm{T}$ lymphocytes as representatives of immunocytes despite we are fully aware of the complicated interaction within the body, such as NK cells, CD4 ${ }^{+} \mathrm{T}$ lymphocytes. However, the impact of NK cells and $\mathrm{CD}^{+} \mathrm{T}$ lymphocytes in human IDD remains unknown. Further studies are needed to address these issues.

Fig 3. Flow cytometry apoptosis analysis of immunocytes after co-cultures. A. Contour diagram of Annexin V-FITC/PI FCM of human NP cells. The graphs stand for typical results of cell apoptosis; values represent the means for three experiments. B. Comparison of apoptotic cells in various macrophages groups $(* p<0.05)$. Data are representative of three experiments. Error bars represent SEM. C. Comparison of apoptotic cells in various $C D 8^{+} T$ cell groups $(* p<0.05)$. Data are representative of three experiments. Error bars represent SEM.

\section{Conclusions}

The study is the first in successfully establishing an in vitro model addressing the interaction of human NP cells and immunocytes. Our study clarifies the mechanisms of the role of FasL-Fas network in human NP and shed light on the derivation of FasL in human disc.

\section{Acknowledgements}

This work was supported by Chinese National Natural Science Foundation Grants (No.30901509, No.81270028, No.81171747, No.81271342, and No.30972883). We thank Jin-Tao Hu for her assistance in FCM analysis; Dan Li for helping obtain cadaveric specimens.

\section{Competing Interests}

The authors have declared that no competing interest exists.

\section{References}

1. Richardson SM, Mobasheri A, Freemont AJ, Hoyland JA. Intervertebral disc biology, degeneration and novel tissue engineering and regenerative medicine therapies. Histology and histopathology. 2007; 22: 1033-41.

2. Waddell G. Low back pain: a twentieth century health care enigma. Spine. 1996; 21: 2820-5. 
3. Stokes IA, Iatridis JC. Mechanical conditions that accelerate intervertebral disc degeneration: overload versus immobilization. Spine. 2004; 29: 2724-32.

4. Jones P, Gardner L, Menage J, Williams GT, Roberts S. Intervertebral disc cells as competent phagocytes in vitro: implications for cell death in disc degeneration. Arthritis research \& therapy. 2008; 10: R86. doi:10.1186/ar2466.

5. Tschoeke SK, Hellmuth M, Hostmann A, Robinson Y, Ertel W, Oberholzer A, et al. Apoptosis of human intervertebral discs after trauma compares to degenerated discs involving both receptor-mediated and mitochondrial-dependent pathways. Journal of orthopaedic research : official publication of the Orthopaedic Research Society. 2008; 26: 999-1006. doi:10.1002/jor.20601.

6. Aladin DM, Cheung KM, Chan D, Yee AF, Jim JJ, Luk KD, et al. Expression of the Trp2 allele of COL9A2 is associated with alterations in the mechanical properties of human intervertebral discs. Spine. 2007; 32: 2820-6. doi:10.1097/BRS.0b013e31815b75c5.

7. Wang $\mathrm{HQ}, \mathrm{Yu} \mathrm{XD}$, Liu ZH, Cheng $\mathrm{X}$, Samartzis D, Jia LT, et al. Deregulated miR-155 promotes Fas-mediated apoptosis in human intervertebral disc degeneration by targeting FADD and caspase-3. The Journal of pathology. 2011; 225: 232-42. doi:10.1002/path.2931.

8. Buckwalter JAMV, Boden SD, Eyre DR, Weidenbaum M. Orthopaedic Basic Science: Biology and Biomechanics of the Musculoskeletal System. Rosemont: American Academy of Orthopaedic Surgeons. 2000.

9. Bobechko WP, Hirsch C. Auto-Immune Response to Nucleus Pulposus in the Rabbit. The Journal of bone and joint surgery British volume. 1965; 47: 574-80.

10. Park JB, Lee JK, Park SJ, Kim KW, Riew KD. Mitochondrial involvement in fas-mediated apoptosis of human lumbar disc cells. The Journal of bone and joint surgery American volume. 2005; 87: 1338-42. doi:10.2106/JBJS.D.02527.

11. Geiss A, Larsson K, Rydevik B, Takahashi I, Olmarker K. Autoimmune properties of nucleus pulposus: an experimental study in pigs. Spine. 2007; 32: 168-73. doi:10.1097/01.brs.0000251651.61844.2d

12. Lee HO, Ferguson TA. Biology of FasL. Cytokine \& growth factor reviews. 2003; 14: 325-35.

13. Griffith TS, Brunner T, Fletcher SM, Green DR, Ferguson TA. Fas ligand-induced apoptosis as a mechanism of immune privilege. Science. 1995; 270: 1189-92.

14. Hunt JS, Vassmer D, Ferguson TA, Miller L. Fas ligand is positioned in mouse uterus and placenta to prevent trafficking of activated leukocytes between the mother and the conceptus. J Immunol. 1997; 158: 4122-8.

15. Stuart PM, Griffith TS, Usui N, Pepose J, Yu X, Ferguson TA. CD95 ligand (FasL)-induced apoptosis is necessary for corneal allograft survival. The Journal of clinical investigation. 1997; 99: 396-402. doi:10.1172/JCI119173.

16. Swenson KM, Ke B, Wang T, Markowitz JS, Maggard MA, Spear GS, et al. Fas ligand gene transfer to renal allografts in rats: effects on allograft survival. Transplantation. 1998; 65: 155-60.

17. Takeuchi $T$, Ueki $T$, Nishimatsu H, Kajiwara $T$, Ishida $T$, Jishage $K$, et al. Accelerated rejection of Fas ligand-expressing heart grafts. J Immunol. 1999; 162: 518-22.

18. Ke B, Coito AJ, Kato H, Zhai Y, Wang T, Sawitzki B, et al. Fas ligand gene transfer prolongs rat renal allograft survival and down-regulates anti-apoptotic Bag-1 in parallel with enhanced Th2-type cytokine expression. Transplantation. 2000; 69: 1690-4.

19. Lai JH, Ho LJ, Lu KC, Chang DM, Shaio MF, Han SH. Western and Chinese antirheumatic drug-induced $\mathrm{T}$ cell apoptotic DNA damage uses different caspase cascades and is independent of Fas/Fas ligand interaction. J Immunol. 2001; 166: 6914-24.

20. Tourneur L, Malassagne B, Batteux F, Fabre M, Mistou S, Lallemand E, et al. Transgenic expression of CD95 ligand on thyroid follicular cells confers immune privilege upon thyroid allografts. J Immunol. 2001; 167: 1338-46.

21. Park JB, Kim KW, Han CW, Chang H. Expression of Fas receptor on disc cells in herniated lumbar disc tissue. Spine. 2001; 26: 142-6.

22. Takada T, Nishida K, Doita M, Kurosaka M. Fas ligand exists on intervertebral disc cells: a potential molecular mechanism for immune privilege of the disc. Spine. 2002; 27: 1526-30.

23. Kaneyama S, Nishida K, Takada T, Suzuki T, Shimomura T, Maeno K, et al. Fas ligand expression on human nucleus pulposus cells decreases with disc degeneration processes. Journal of orthopaedic science : official journal of the Japanese Orthopaedic Association. 2008; 13: 130-5. doi:10.1007/s00776-007-1204-4.

24. Depraetere V, Golstein P. Fas and other cell death signaling pathways. Seminars in immunology. 1997; 9: 93-107. doi:10.1006/smim.1997.0062.
25. Park JB, Chang H, Kim KW. Expression of Fas ligand and apoptosis of disc cells in herniated lumbar disc tissue. Spine. 2001; 26: 618-21.

26. Pfirrmann CW, Metzdorf A, Zanetti M, Hodler J, Boos N. Magnetic resonance classification of lumbar intervertebral disc degeneration. Spine. 2001; 26: 1873-8.

27. Zhao CQ, Jiang LS, Dai LY. Programmed cell death in intervertebral disc degeneration. Apoptosis : an international journal on programmed cell death. 2006; 11: 2079-88. doi:10.1007/s10495-006-0290-7.

28. Bechmann I, Mor G, Nilsen J, Eliza M, Nitsch R, Naftolin F. FasL (CD95L, Apo1L) is expressed in the normal rat and human brain: evidence for the existence of an immunological brain barrier. Glia. 1999; 27: 62-74.

29. Bellgrau D, Gold D, Selawry H, Moore J, Franzusoff A, Duke RC. A role for CD95 ligand in preventing graft rejection. Nature. 1995; 377: 630-2. doi:10.1038/377630a0.

30. Runic R, Lockwood CI, Ma Y, Dipasquale B, Guller S. Expression of Fas ligand by human cytotrophoblasts: implications in placentation and fetal survival. The Journal of clinical endocrinology and metabolism. 1996; 81: 3119-22.

31. Inui $Y$, Nishida K, Doita M, Takada T, Miyamoto H, Yoshiya S, et al. Fas-ligand expression on nucleus pulposus begins in developing embryo. Spine. 2004; 29: 2365-9.

32. Olmarker K, Blomquist J, Stromberg J, Nannmark U, Thomsen P, Rydevik B. Inflammatogenic properties of nucleus pulposus. Spine. 1995; 20: 665-9.

33. Satoh K, Konno S, Nishiyama K, Olmarker K, Kikuchi S. Presence and distribution of antigen-antibody complexes in the herniated nucleus pulposus. Spine. 1999; 24: 1980-4

34. Gertzbein SD, Tile M, Gross A, Falk R. Autoimmunity in degenerative disc disease of the lumbar spine. The Orthopedic clinics of North America. 1975; 6: 67-73

35. Marshall LL, Trethewie ER, Curtain CC. Chemical radiculitis: A clinical, physiological and immunological study. Clinical orthopaedics and related research. 1977;: 61-7.

36. Chervonsky AV, Wang Y, Wong FS, Visintin I, Flavell RA, Janeway CA, Jr, et al. The role of Fas in autoimmune diabetes. Cell. 1997; 89: 17-24.

37. Lowin B, Hahne M, Mattmann C, Tschopp J. Cytolytic T-cell cytotoxicity is mediated through perforin and Fas lytic pathways. Nature. 1994; 370: 650-2. doi:10.1038/370650a0.

38. Kagi D, Vignaux F, Ledermann B, Burki K, Depraetere V, Nagata S, et al. Fas and perforin pathways as major mechanisms of $\mathrm{T}$ cell-mediated cytotoxicity. Science. 1994; 265: 528-30.

39. Theofilopoulos AN, Balderas RS, Gozes Y, Aguado MT, Hang LM, Morrow PR, et al. Association of lpr gene with graft-vs.-host disease-like syndrome. The Journal of experimental medicine. 1985; 162: 1-18.

40. Dittel BN, Merchant RM, Janeway CA, Jr. Evidence for Fas-dependent and Fas-independent mechanisms in the pathogenesis of experimental autoimmune encephalomyelitis. J Immunol. 1999; 162: 6392-400.

41. Su X, Hu Q, Kristan JM, Costa C, Shen Y, Gero D, et al. Significant role for Fas in the pathogenesis of autoimmune diabetes. J Immunol. 2000; 164: 2523-32.

42. Nagata S. Apoptosis by death factor. Cell. 1997; 88: 355-65.

43. Nagata S, Golstein P. The Fas death factor. Science. 1995; 267: 1449-56. 